\title{
Research on the Construction and Implementation of Outstanding Engineering Talents Training Pattern
}

\author{
Changhe $\mathrm{Li}^{*}$ \\ School of Mechanical Engineering \\ Qingdao University of Technology \\ 266520 Qingdao, China \\ sy_lichanghe@163.com \\ Hengshan Yang* \\ Inner Mongolia University for Nationalities \\ 028000 Tongliao, China \\ 13947519082@163.com \\ Yinbin Zhang \\ School of Mechanical Engineering \\ Qingdao University of Technology \\ 266520 Qingdao, China
}

\author{
Yali Hou \\ School of Mechanical Engineering \\ Qingdao University of Technology \\ 266520 Qingdao, China
}

\author{
Jianjun Yang \\ School of Mechanical Engineering \\ Qingdao University of Technology \\ 266520 Qingdao, China
}

\author{
Dongzhou Jia \\ Inner Mongolia University for Nationalities \\ 028000 Tongliao, China
}

\author{
Chengjun Chen \\ School of Mechanical Engineering \\ Qingdao University of Technology \\ 266520 Qingdao, China
}

\begin{abstract}
Cultivation of engineering technical talents is a necessary guarantee for developing strategic emerging industries and constructing new-type industrialized country, an intellectual guarantee for constructing an innovation-originated nation, and also an inevitable requirement for strengthening China's comprehensive economic strength and further fusing into global economic integration. This paper elaborates the state of the "Outstanding Engineer Education and Training Plan". For bottleneck problems: it's difficult for present engineering talents training to adapt to new industrial demand, how to establish innovative-type talents training pattern and teaching system under the new situation, we have carried out in-depth research on teaching quality engineering construction and teaching reform pattern. On this basis, a new outstanding engineering talent training pattern taking professional theoretical knowledge learning, comprehensive engineering quality and innovative \& entrepreneurial ability as training objectives has been established.
\end{abstract}

Keywords-outstanding engineering talents training; innovation; teaching system; independent research

\section{STATE OF THE ART}

In order to further deepen higher engineering educational reform, Ministry of Education together with relevant department and guild (industrial association) jointly implemented "Outstanding Engineer Education and Training Plan” in June, 2010. This plan is a significant reform project of National Outline for Medium and Long-term Educational Reform and Development Planning (2010-2020) and National Outline for Medium and Long-term Talent Development Planning (2010-2020). The outstanding plan orients at industrial circles, the world and the future to cultivate a batch of various types of high-quality engineering technical talents who can adapt to economic and social development requirements with strong innovation capacity so as to lay a solid foundation for constructing an innovation-originated nation, realizing industrialization and modernization, exerting human resource advantages, enhancing national core competitiveness and comprehensive national strength ${ }^{[1]}$.

Since Outstanding Plan was carried out in 2010, there have been more than 300 colleges and universities which participate into Outstanding Plan in three batches. From national implementation of innovation-driven development strategies, 
the fundamental point lies in force of science and technology and the key lies in vigorous improvement of capability of independent innovation, which constitute the core of national implementation of development strategies and key of improvement of comprehensive national strength. Although engineering talent output scale in colleges and universities in China takes the first place within global scope, some alarming bottleneck problems simultaneously exist ${ }^{[2]}$.

Engineer training ability and absolute number of engineers in China is the number one in the world, but number of highquality engineers is far lower than world average level. As a world superpower, China takes the 28th place in 2014-2015 Global Competitiveness Report issued by World Economic Forum in 2014. Shortage of high-quality engineers has influenced development of comprehensive competitiveness of China. Survey published by McKinsey \& Co in 2015 showed that: proportion of engineers with global competitiveness in China was $10 \%$ of total number of engineers, while this figure in America was 80\%.

The contradiction between engineering graduates and enterprise demand becomes prominent. College education is disjointed from market demand, much more emphasis is given to theory than practice, and consequently, the cultivated students can't adapt to social requirements. On the one hand, with enlarging enrollment scale of colleges and universities, employment difficulty problem of graduates becomes increasingly severe, and on the other hand, industrial enterprises in urgent need of engineering talents can't recruit proper talents. This contradiction has brought forward new demand for higher engineering education, and higher engineering educational reform is imperative.

There are many internal problems of colleges and universities. In order to elevate their grades, not a few colleges and universities put their main efforts in development of scientific research, talents training modes are quite single, educational pattern for cultivating scientific research talents is used to train engineering students, and curriculum system setting can't adapt to modern engineering characteristics. Practical curriculum is in shortage in the teaching process so that students' practical and operational abilities can't be exercised. Due to large quantity of students, great contrast exists between practical requirements and practical conditions, it's difficult for students to contact real industrial environment with few operating opportunities. Colleges and universities have neglected cultivation of students' innovation capability, and under the long-term influence of exam-oriented education, students lack abilities of independently thinking and solving problems. Colleges and universities rarely open curriculums in aspects of logic communication and vocational guidance, etc., and as a result, most students have deficient abilities of correctly thinking and interpersonal communication. Engineering teachers lack engineering practical background, on the one hand, in most colleges and universities are "college to college" teachers who have solid theoretical knowledge but commonly lack engineering experience, and on the other hand, engineers who have experience in enterprises can hardly enter classrooms, therefore, students' engineering practical ability and innovation capability can't be trained.
Colleges and universities have been apart from industrial circles with a lack of win-win cooperative pattern. Influenced by original teaching system, educational circles come apart from industrial circles. On the one hand, colleges and universities can't obtain guidance from industrial circles in aspect of engineering talents training scale, and consequently, the cultivated students can't adapt to market demand and their employment competitiveness is not strong. On the other hand, as production units of profit maximization, industrial enterprises lack enthusiasm for cooperating with colleges. Enterprises and public institutions become the first batch of national-level construction units of engineering practical education center. As number of college and university participants increases, Outstanding Plan has been gradually refined from rough guiding outline when it's put forward towards materialization and standardization. More and more scholars have carried out researches on concrete links of implementation of Outstanding Plan involving various aspects like talent training project, talent training pattern, universityindustry-study collaboration, teaching staff construction, etc.

\section{RESEARCH CONTENTS, OBJECTIVES AND Key PROBLEMS PlANNED TO BE SOLVED}

For bottleneck problems: it's difficult for present engineering talents training to adapt to new industrial demand, how to establish innovative-type talents training pattern and teaching system under the new situation, etc., depending on 2 national-level talents training bases in our college and combining Chinese and foreign colleges and practice bases, we have carried out in-depth research on teaching quality engineering construction and teaching reform pattern. Based on clear understanding of educational philosophy and talents training objective, a three-layer progressive in-class project system, three-order promotion-type extracurricular scientific and technological innovation platform and tricyclic complementary college-enterprise joint training system have been gradually established. On this basis, a new outstanding engineering talent training pattern taking professional theoretical knowledge learning, comprehensive engineering quality and innovative \& entrepreneurial ability as training objectives has been established ${ }^{[3]}$.

\section{A. Research contents}

1) Construct “five-in-one” teaching system conforming to professional certification requirements of "Washington Accord" and combining teaching, scientific research and production

Taking improvement of students' comprehensive engineering quality and innovative \& entrepreneurial ability as the objective and based on OBE concept, we have comprehensively analyzed graduation requirements of engineering students and refined them into training objectives, and we have elaborately designed ability matrix facing integration of theoretical knowledge learning and comprehensive quality. For outstanding plan curriculum teaching, teaching reform is deepened by centering on ability to transform "knowledge classroom” into “ability classroom”. We have conducted comprehensive reform and practice in aspects of teaching contents and curriculum system, teaching method 
and means, experimental and curriculum design and teaching evaluation to reconstruct teaching contents and pattern for series of curriculums of machine design and manufacturing and its automation specialty. We have explored into and constructed "five-in-one" teaching system including: exquisite theoretical classroom explaining, team-based experiencing-type interactive discussion curriculum and project group design, independent investigation-type experimental workshop, team competition-based comprehensive practical training-type research project and innovative and practical-type graduation $\operatorname{design}^{[4]}$.

Teaching method and means reform is sally port for realization of engineering educational ability achievement objective. For engineering educational ability achievement requirements, we have constructed new teaching method and means for machinery series of curriculums, and put efforts in promoting multiple investigative learning methods like projectbased learning and case-based learning, etc. Multiple forms and paths are used to expand students' scope of knowledge and engineering experience. Through effective exchange ad activity organization, we aim at improving students' expression ability when communicating with others, and actively encouraging innovative thinking, cultivating and improving students' engineering practice ability, engineering design ability and engineering innovation ability in practical activities.

Among all types of teaching methods adopted by foreign famous colleges, the one which is mostly appropriate for engineering education is investigative learning method based on issue and project (it can be called investigative teaching method for teachers), and it's a teaching organization form and teaching method which accords with engineering ability training rules and comprehensive quality formation logic.

Project teaching method is a teaching method orienting at engineering practice and fully embodying modern educational concept, and it has been widely applied in western countries especially Germany with significant effect. Project teaching method is a practical teaching activity implemented to finish a complete "project", it arranges knowledge and skills involved in multiple courses to students through a definite "project task", and students utilize learned knowledge and skills according to task requirements, and based on 5 phases "define project tasksformulate work plan-organize project implementation-check assessment and evaluation-conclude appraisal files", "team learning" method is adopted to finally complete project tasks and present them in form of achievements through beating brain, operation, communication and cooperation.

For engineering educational ability achievement objective, conception, design, realization and operation pattern-centered advanced teaching methods which orient problems and projects should be introduced into teaching method and means reform for outstanding plan series of curriculums. We have carried out research on multiple investigative learning methods like problem-based learning, project-based learning and case-based learning so that subject and project exploration will run through the whole teaching process.

Set up three-layer progressive in-class project system, three-order promotion-type extracurricular scientific and technological innovation platform and tricyclic complementary college-enterprise joint training system to form spiral escalation-type "circles within circles three-three-three" outstanding engineering talents training pattern.

Taking improving students' comprehensive engineering quality and innovative \& entrepreneurial ability as the objective, we have established three-layer "curriculum research program (curriculum level-three program), comprehensive application program (curriculum group level-two program and engineering research \& development program (innovation competition and comprehensive graduation design)"in-class program system integrating teaching, scientific research and production; Depending on innovation base and national-level and provincial-level competition platforms, we have constructed an omnibearing and three-dimensional third-order (including basic skill competition, innovative design competition and entrepreneurial planning competition) promotion-type extracurricular scientific \& technological innovation platform containing different grades so as to form a practical teaching system with in-class and extracurricular integration and complementation; on-campus practice and training, off-campus substituted post practice and off-campus graduation design are integrated into and run through talents training system in outstanding plan to construct tricyclic complementary college-enterprise joint training system and form college-enterprise joint training pattern with in-depth interaction and integration of on-campus learning and enterprise practice ${ }^{[5]}$.

2) Construct process-based hierarchical and graded teaching evaluation standard which can comprehensively assess students' knowledge, ability and quality and form accurate output-oriented ability achievement evaluation system with controllable quantification and multichannel feedback

Taking improving students' comprehensive engineering quality and innovative \& entrepreneurial ability as the main line and based on graduation requirements and detailed ability indexes, we have elaborately designed assessment indexes of various links like classroom attendance, regular assignment, experimental performance, discussion section, curriculum program and results exam ${ }^{[6]}$. We have creatively proposed market analysis and prediction, cost analysis and assessment and self-evaluation and mutual evaluation in program and graduation practice link and introduced them into competitiontype assessment mechanism.

\section{B. Research objectives}

1) Carry out a research on "five-in-one" teaching system namely exquisite theoretical classroom explaining, team-based experiencing-type interactive discussion curriculum and project group design, independent investigation-type experimental workshop, team competition-based comprehensive practical training-type research project and innovative and practical-type graduation design.

For common bad learning habits of colleges students like poor initiative, overdependence on teachers, etc., we have continuously explored in teaching practice and changed the past "duck-stuffing" teaching method to construct a "five-inone” teaching system including exquisite theoretical classroom 
explaining, team-based experiencing-type interactive discussion curriculum and project group design, independent investigation-type experimental workshop, team competitionbased comprehensive practical training-type research project and innovative and practical-type graduation design so as to realize deep integration and spiral-type promotion of "professional theoretical knowledge learning" and "cultivation of comprehensive engineering quality”. Heuristic guidance, scenario creating, objective setting, program giving and discussion adding and other ways are adopted to highlight subject position of students and leading role of teachers, guide students' interest in seeking knowledge, help students to establish correct thinking mode, research method and learning method and let students transform from "asked to learn" into "want to learn". The platform is provided to students for selflearning, exploration and innovation and assistance in completing teaching contents by setting discussion section and programs, which not only guarantees cultivation of batches of qualified engineering talents but also realizes student-centered individualized cultivation so that their engineering quality will be greatly improved.

2) Construct a new win-win college-enterprise joint training pattern with deep interaction and integration of oncampus learning and enterprise practice.

Since 2010, School of Mechanical Engineering of Qingdao Technological University has gradually established favorable practical cooperative relationships with many enterprises in mechanical industry, constructed off-campus practice base and signing base for practice contract, utilized enterprise equipment and practical conditions, promoted combination of production, teaching and research and commercialization of research findings, set up a talents training system integrating enterprisecentered technological innovation and college-centered knowledge innovation and realized organic integration and effective interaction of curriculum program, teaching content and scientific research as well as production practice ${ }^{[7]}$. Through the linkage with excellent enterprise cultures, we have integrated value ideas and management ideas of outstanding enterprises into daily teaching process and used all possible paths and forms to guide students and permeate knowledge into students so that students can set up correct enterprise value concept and enhance their comprehensive engineering quality and innovative \& entrepreneurial ability. Besides, we have created innovative \& entrepreneurial engineering talents training platform so as to narrow the gap between engineering talents training and actual social demand.

3) Study output-oriented and process-based ability achievement evaluation method with controllable quantification.

Existence of the above problems directly affects cultivation and elevation of engineering practice ability of outstanding engineers. It's necessary to deeply carry out teaching quality engineering construction and teaching reform work. Based on clear understanding of educational philosophy and talents training objective, "three-level progressive in-class project system, three-stair-type extracurricular scientific and technological innovation platform and tricyclic complementary college-enterprise joint "three-three-three" outstanding engineering talent training pattern should be deeply studied to construct process-based hierarchical graded teaching evaluation standard which can comprehensively assess students' knowledge, ability and quality and form accurate outputoriented ability achievement evaluation system with controllable quantification and multi-channel feedback", and on this basis, a new outstanding engineering talent training pattern taking professional theoretical knowledge learning, comprehensive engineering quality and innovative \& entrepreneurial ability as training objectives should be established $^{[8]}$.

\section{Key problems planned to be solved}

1) Build an "excellent theoretical class explanation, discussing interactive courses based on team experience, independent research-based experimental workshop, team competition model research based on the comprehensive training, innovative practical graduation design” five integrated teaching system;

2) Build a three-tier progressive curriculum system, a three-step after-school science and technology innovation platform, and a joint training system for the three-ring complementary school enterprises;

3) Build a "process based, output oriented, quantitative controllable, multi-channel feedback" evaluation system.

\section{SUMMARY}

We have carried out a research on curriculum teaching assessment method namely "output-oriented and process-based ability achievement evaluation method with controllable quantification”, which ensures that students can participate in the whole teaching process in system so that scientific and research evaluation on students' ability and quality can be made.

Core curriculum group programs and curriculum programs have independent research and design contents, assessment nodes, assessment and marking criteria, design report, demonstration reporting, etc.

We have incorporated students' classroom attendance, regular assignment, experimental performance, quiz, discussion section, program performance and performance in final exam and other links into curriculum assessment index system to comprehensively assess their knowledge, ability and quality and implement whole-process management of students' curriculum learning. In this way, students can actively participate in teaching activities in the whole process and we can comprehensively assess students' learning attitude, their abilities of mastering and utilizing knowledge and their operative and practical abilities so as to powerfully promote construction of learning style and exam environment.

We have sufficiently motivated students' initiative in participating in curriculum teaching and stimulated their interest in initiatively exploring and thinking with an aim at prominent improvement of attendance rates of different curriculums, average scores and quality of curriculum design and graduation design ${ }^{[8]}$. 


\section{ACKNOWLEDGMENT}

This research was financially supported by the teaching reform research project of higher education in shandong province (Z2016Z011; 2012042 and 2015M087)

\section{REFERENCES}

[1] Changhe Li, Yali Hou, and Jianjun Yang, "Research on Project-Driven Teaching Method of Technology of Mechanical Manufacture Based on Ability Training," International Journal of Information and Education Technology, Vol. 7, No. 6, 2017: 474-478

[2] Y. L. Hou and C. H. Li, "The research and practice on the integrated optimization of the machinery manufacturing joint curriculum group platform,” Advances in Social and Behavioral Sciences, vol.6, pp.1016,2014 .
[3] R. F. Wang, "Combination of traditional teaching and interactive teaching,” The Border Economy and Culture, vol.12, pp.63-72, 2011.

[4] C. H. Li, Y. L. Hou, J. J. Yang, H. B. Lan, "The Construction of practical teaching system and innovative talent training mode in the fundamental course of mechanic manufacturing," Advances in Education Research, vol.54, pp.7-12,2014.

[5] P. Różewski, O. Zaikin, "Integrated mathematical model of competence-based learning-teaching process," Bulletin of the Polish Academy of Sciences Technical Sciences, vol. 63, pp. 245-259, 2015.

[6] F. Peng, F. X. Xiao, and Y. L. Wang, "Improving experiment examination method and Cultivating innovative talents,” The journal of Science and education, vol.12, pp.192, 2008.

[7] L. P. Gu, "Practical teaching system construction in higher vocational colleges,” China's higher education research, vol.11, pp.67-68, 2005.

[8] J. Jiang, "Mechanical manufacturing basis curriculum project teaching method in the exploration and practice," Journal of Anhui technical college of electrical engineering, vol.4, pp.95-98, 2005. 